See discussions, stats, and author profiles for this publication at: https://www.researchgate.net/publication/319575292

\title{
EFFECT OF POLYMER CHAIN MODIFICATIONS ON ELASTOMER PROPERTIES
}

Article in Rubber Chemistry and Technology · September 2017

DOI: 10.5254/RCT.18.82685

CITATION

1

6 authors, including:

Katarzyna Bandzierz

Lodz University of Technology

10 PUBLICATIONS 15 CITATIONS

SEE PROFILE

W. K. Dierkes

University of Twente

93 PUBLICATIONS 735 CITATIONS

SEE PROFILE
D. Jerzy Dryzek

Institute of Nuclear Physics

149 PUBLICATIONS 769 CITATIONS

SEE PROFILE

Anke Blume

University of Twente

77 PUBLICATIONS 71 CITATIONS

SEE PROFILE

Some of the authors of this publication are also working on these related projects:

Tire treads View project

Project Silica Reinforced Natural Rubber View project 
Accepted for publication in: Rubber Chemistry and Technology

\title{
EFFECT OF POLYMER CHAIN MODIFICATIONS ON ELASTOMER
}

\section{PROPERTIES}

\author{
KATARZYNA S. BANDZIERZ ${ }^{1 *}$, LOUIS A. E. M. REUVEKAMP ${ }^{2}$, JERZY DRYZEK ${ }^{3}$, WILMA K. DIERKES ${ }^{2}$, ANKE \\ BLUME $^{2}$, DARIUSZ M. BIELIŃSKI ${ }^{1}$ \\ 1 Institute of Polymer And Dye Technology, Lodz University of TeChnology, Lodz, Poland \\ 2 Elastomer Technology \& Engineering, University of Twente, Enschede, The Netherlands \\ 3 Institute of Nuclear Physics, Polish Academy of Sciences, Krakow, Poland \\ * Corresponding author. Email: katarzyna.bandzierz@gmail.com
}

\begin{abstract}
Considerable attention is paid to the influence of crosslink density and crosslink structures on behavior of polymer chains and properties of elastomers. However, a very important parameter seems to be underestimated: the modifications to the polymer chains by curatives, formed by sulfur and fragments of accelerators. The present paper intends to draw attention to this important contribution to performance of spatial networks. The emulsion styrene-butadiene rubber (E-SBR) samples, cured with tetramethylthiuram disulfide and sulfur $\left(\mathrm{TMTD} / \mathrm{S}_{8}\right)$, and zinc dialkyl dithiophosphate with sulfur $\left(\mathrm{ZDT} / \mathrm{S}_{8}\right)$, were studied. They were characterized in detail in terms of crosslink density and crosslink structures. Microscale techniques were used to obtain information about the behavior of the polymer chains: PALS to study the free volume structure; DSC and DMA to monitor the glass transition process. Properties such as static mechanical performance and thermo-oxidative stability were also evaluated. All the investigated characteristics were influenced by a combination of crosslink density, crosslink structures and to a large extent, by the modifications of the polymer chains. The effect of the modifications is dependent on the amount and the structure of the curatives' molecules. On the basis of the obtained results, the usefulness of "phr" unit used for calculation of the curatives' amount has been queried. Furthermore, it has been demonstrated that DSC, DMA and PALS techniques can provide evidence for the presence of the modifications on the polymer chain by curatives.
\end{abstract}

\section{INTRODUCTION}

Widespread use of elastomers became possible when Charles Goodyear and Thomas Hancock discovered the ability of sulfur to form chemical bonds between the polymer chains. ${ }^{1-4}$ Sulfur curing made the 
dimensions of elastomer products more stable in a range of temperatures and conditions, and improved numerous physical and chemical properties. Further development in the elastomer technology was stimulated through the use of curing accelerators. ${ }^{1-6}$ These organic components served to shorten the curing time and additionally improve the properties. Till present times, the most common way of elastomer curing is based on use of accelerated sulfur curing systems.

Accelerated sulfur curing is a very complicated process, hence various mechanisms are proposed. Despite differences, there is a general agreement about the basic steps, as proposed by Morrison and Porter ${ }^{7}$ (Figure 1).

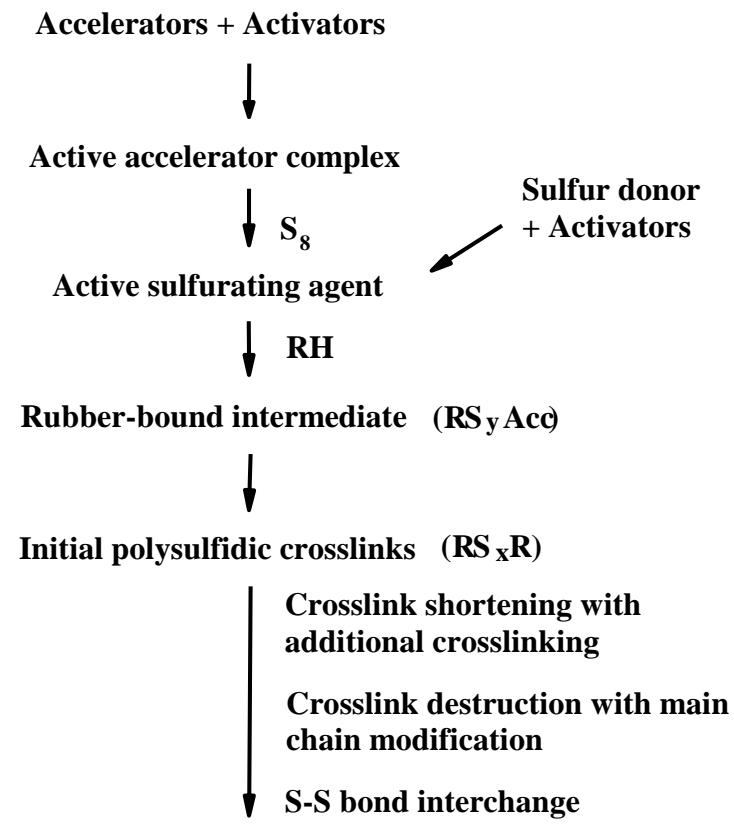

Final vulcanizate network

FIG. 1. - Outline reaction scheme for the accelerated sulfur curing of diene rubbers (R represents the rubber chain; Acc is the accelerator residue).

During the curing process, one of the critical steps is the formation of polysulfidic acceleratorterminated pendant groups $\left(\mathrm{RS}_{\mathrm{y}} \mathrm{Acc}\right)$. $^{1,4-21}$ These crosslinks precursors are bound to the polymer chains. Further, they react with other pendant groups or directly with the polymer chains. ${ }^{5,21}$ In this way, intermolecular crosslinks are formed, which connect the chains. The number of crosslinks per unit volume in a polymer network is called crosslink density. ${ }^{22}$ Since intermolecular crosslink are elastically effective, they influence to a very high extent multiple properties of the elastomer materials. ${ }^{1,3,4,7,23-26}$ Hence, the crosslink density is a basic structural parameter characterizing the polymer networks. Crosslinks formed in a process of accelerated sulfur curing can 
have various structures. Short, rigid bonds created directly between polymer chains are carbon-carbon (C-C) crosslinks. Sulfidic crosslinks are longer and consist of sulfur atoms incorporated between the polymer chains. Depending on the number of these atoms, they are classified as monosulfidic $(\mathrm{C}-\mathrm{S}-\mathrm{C})$, disulfidic $\left(\mathrm{C}-\mathrm{S}_{2}-\mathrm{C}\right)$ and polysulfidic $\left(C-S_{x}-C, x \geq 3\right)$ crosslinks. Since all these crosslinks have different structures and length, they show different characteristics. It is believed that the type of crosslinks is another structural parameter, which strongly influences the behavior of the polymer chains and resulting properties of the material. ${ }^{1,3,4,7,15,16,18,23-28}$ Due to this, much attention is devoted to the crosslink density and structures analyses, and interpretation of the macroscopic properties in the context of these parameters.

The reactivity of sulfur and complex organic compounds having various reactive groups is very complex $^{29}$, especially at elevated temperature. As a result, beside formation of intermolecular crosslinks, various side reactions can occur during the curing proces,s. ${ }^{1,3,7,11,12,15,18,23,24,25}$ As a result of them, the curatives bond chemically to the polymer chains without formation of the elastically effective crosslinks. Part of the polysulfidic accelerator-terminated pendant groups, being crosslink precursors, can remain in this form. Furthermore, the sulfur chains can bond to two places on one polymer chain and form in this way cyclic sulfidic structures, most probably having one or two sulfur atoms. Possible structures in the polymer network, formed during the accelerated sulfur curing process, are schematically illustrated in Figure 2., 3,4,10,12,15,28,29

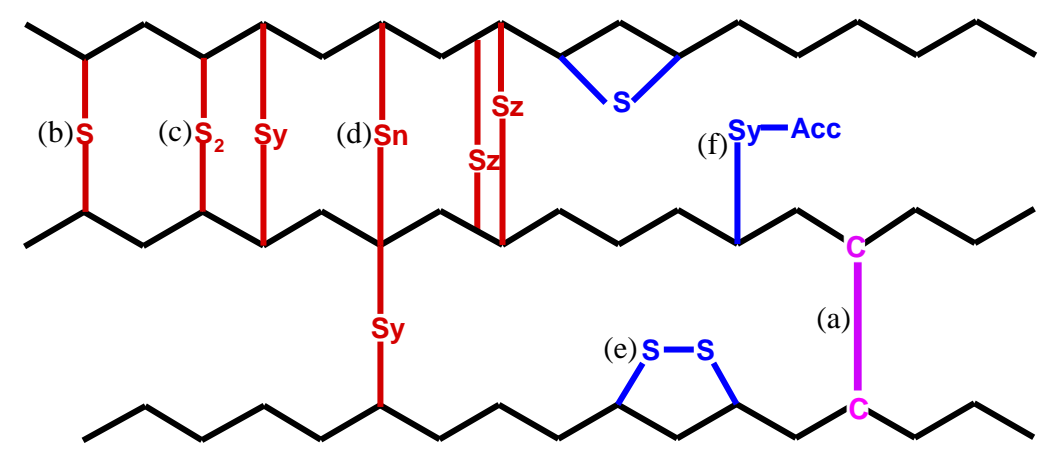

FIG. 2. - Scheme of network structure and structures formed as a result of accelerated sulfur curing intermolecular crosslinks: (a) carbon-carbon crosslink; (b) monosulfidic crosslink (C-S-C); (c) disulfidic crosslinks $\left(\mathrm{C}-\mathrm{S}_{2}-\mathrm{C}\right)$; (d) polysulfidic crosslink $\left(\mathrm{C}-\mathrm{S}_{x}-\mathrm{C}, \mathrm{x} \geq 3\right)$; - intramolecular modifications of the polymer chains: (e) cyclic sulfidic structure; (f) pendant sulfidic group terminated with accelerator moiety. 
The influence of the intramolecular modifications on the elastomer properties remains controversial. In the subject literature these structural features are sometimes considered as having almost no influence on the behavior of the polymer chains. ${ }^{3}$ In other works, the possible influence of these structural features was evaluated. 1,7,12,14,15,17,23-25,28,30 The formed modifications were investigated with use of ${ }^{14} \mathrm{C}$-labeled accelerators ${ }^{11-14}$, dual labeled system: ${ }^{3} \mathrm{H}$-labeled accelerator and elemental ${ }^{35} \mathrm{~S}^{13,14},{ }^{13} \mathrm{C} \mathrm{NMR}^{19,20}$, chemical analyses ${ }^{8,9}$, spectral methods ${ }^{8,31}$. Despite these works, no straightforward, uncomplicated method has been established to analyze the modifications of the chains. This possibly contributes to the fact that currently in research, the influence of the modifications on the behavior of the polymer chains is very rarely considered. Instead, the elastomer properties are explained mainly on the basis of the crosslink density and crosslink structures.

The curatives are added into the system on a weight basis, and their amount is expressed in part per hundred parts of rubber unit - phr. Depending on the amount of added curatives, and the ratio between the accelerator and sulfur, the curing systems are classified ${ }^{2}$ as conventional, semi-efficient and efficient curing systems, as listed in Table I.

TABLE I

CLASSIFICATION OF THE CURING SYSTEMS, BASED ON THE RATIO BETWEEN THE ACCELERATOR AND SULFUR AMOUNTS, CALCULATED IN PHR ${ }^{2}$

\begin{tabular}{cccc}
\hline Curing system & Amount of & Amount of sulfur, & Accelerator to sulfur \\
& accelerator, phr & phr & ratio, - \\
\hline Conventional (CV) & $0.4-1.2$ & $2.0-3.5$ & $0.1-0.6$ \\
Semi-efficient (SEV) & $1.2-2.4$ & $1.0-1.7$ & $0.7-2.5$ \\
Efficient (EV) & $2.0-5.0$ & $0.4-0.8$ & $2.5-12.0$ \\
\hline
\end{tabular}

It is assumed that the crosslink structure is dependent on the ratio between the curatives. ${ }^{1,2,3,4,7,15,18,25,26}$ In the CV curing system, with high sulfur and low accelerator amounts, mainly long polysulfidic crosslinks are formed. At the same time, due to a large amount of sulfur, many cyclic sulfidic structures are developed as nonelastic modifications of the chains.,.$^{2,4,71,15,18,26}$ In the EV curing system, in which the ratio between the accelerator and sulfur is high, the accelerator molecules efficiently react with sulfur. This is due to an increased competition of accelerator fragments for available free sulfur. As a result, short crosslinks are developed, and the 
modifications formed by sulfur are scarce. At the same time, the level of accelerator pendant groups is significantly higher. ${ }^{411,12,15,18}$ When the accelerator to sulfur ratio is between the CV and EV systems, an intermediate crosslink structure is obtained.

The first accelerators used for curing were compounds of small molecules and low molecular weight. ${ }^{1-5}$ With a further development of rubber chemistry, other chemical compounds became applicable for this purpose. Till present times, the progress in rubber chemistry is fast and new accelerators are synthesized and introduced into the market. They have advanced to complex structures with novel reactive groups. Consequently, it makes their molecular weight higher. For the mixture formulations, their amounts are still calculated in phr unit. However, due to their high molecular weight, this unit is not useful. This is caused by the fact that the phr unit does not consider the molecular weight of the accelerator.

Due to complexity of the curing process and very large number of curatives available nowadays, it is necessary to reconsider the structural features formed by them. Crosslink density and crosslink structures are well-established parameters describing the polymer networks. At the same time, it can be valuable to also look closer at the role of the structure of the curatives and modifications formed by them. This can contribute to a better understanding of the network structure of cured elastomers and provide a deeper insight into their structure-property relationships. Therefore, this should be included in all future discussions. The aim of this research was to characterize in detail the structural parameters of the cured elastomer network and determine how they influence the behavior of the polymer chains and properties of the material. This will allow to reach a better understanding between the chemical structure and physical properties, and make the behavior of the polymer network more predictable. For this purpose, two series of samples were studied. The samples were prepared with a typical industrial rubber: E-SBR. They were cured with accelerated sulfur systems: TMTD/S 8 and $\mathrm{ZDT} / \mathrm{S}_{8}$. In the first series, a low-molecular weight accelerator - tetramethylthiuram disulfide (TMTD) - was incorporated. It has been used for long time in the elastomer technology. However, the use of TMTD inside a rubber compound can causes nitrosamines, which pose a serious health hazard. This is why TMTD is no longer used in industry, but in this work it was used only for research purpose. In the second series, zinc dialkyl dithiophosphate (ZDT) was applied, which is a modern accelerator having a complex structure and a high molecular weight. In the series, the crosslink density was determined by equilibrium swelling and calculated on the basis of the Flory-Rehner equation. ${ }^{32}$ The crosslink structures was investigated by the thiol-amine analysis. ${ }^{28}$ The influence of these structural parameters on stiffening of the polymer chains and on the glass transition temperature $\left(T_{g}\right)$ was studied by Differential Scanning Calorimetry (DSC) and Dynamic Mechanical Analysis 
(DMA). Another structural parameter - the free volume size - was studied by Positron Annihilation Lifetime Spectroscopy (PALS). The influence of the network structure on thermo-oxidative properties was checked by Thermogravimetric Analysis (TGA). Static mechanical properties were determined by standard tensile tests. All evaluated properties were correlated with the parameters of the network structure. On the basis of the obtained results, the validity of the phr unit for curatives of various structures was checked.

\section{EXPERIMENTAL}

\section{MATERIALS}

The polymer used in this study was a cold emulsion styrene-butadiene rubber (E-SBR) KER 1500, with $23.5 \%$ of bound styrene, produced by Synthos (Poland). The chemical structure of butadiene consists of $15 \%$ 1.2-vinyl, $10 \%$ 1.4-cis, and 75\% 1.4-trans forms. The molecular weight of the E-SBR was $\mathrm{M}_{\mathrm{n}}=151000 \mathrm{~g} / \mathrm{mol}$, $\mathrm{M}_{\mathrm{w}}=425000 \mathrm{~g} / \mathrm{mol}$, and dispersity 2.8 , as reported by the producer. The Mooney viscosity was ML $(1+4) 100{ }^{\circ} \mathrm{C}$ =50. Zinc oxide and stearic acid were obtained from Arlanxeo (the Netherlands), and rhombic sulfur from Siarkopol Tarnobrzeg (Poland). The curing accelerators - TMTD and ZDT - are characterized in Table II. Acetone used for extraction and toluene used for crosslink density analysis were of analytical grade, obtained from Assink Chemie (the Netherlands). The chemicals for the thiol-amine probes: piperidine (99\%), 2propanethiol ( $\geq 98 \%$ ) and 1-dodecanethiol ( $\geq 98 \%$ ) were provided by Sigma-Aldrich (USA).

\section{TABLE II}

\section{CHARACTERIZATION OF THE CURATIVES USED IN THE EXPERIMENTS}

Molecular formula,

Name (purity; supplier)

TMTD

Tetramethylthiuram disulfide

(96\%; Arlanxeo, the Netherlands)
Structural formula<smiles>CN(C)C(=S)SSC(=S)N(C)C</smiles>

$\mathrm{C}_{6} \mathrm{H}_{12} \mathrm{~N}_{2} \mathrm{~S}_{4}$

$240.43 \mathrm{~g} / \mathrm{mol}$ 


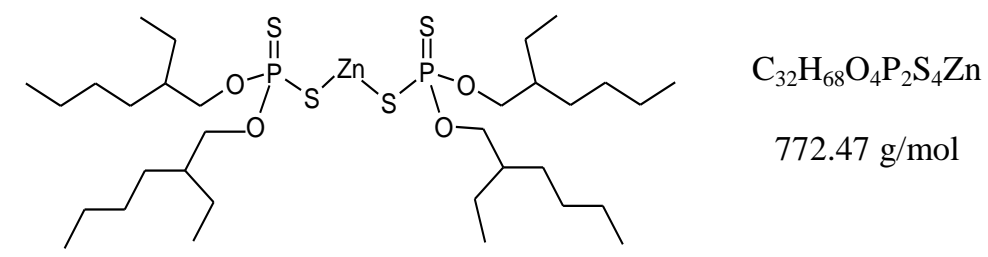
phosphate $^{33}$ (50\%; Arlanxeo, the

Netherlands)

\section{SAMPLE PREPARATION}

Mixing. - The samples were mixed in two steps. The first step was performed in an internal micromixer Brabender Plasti-Corder (Germany) with a mixing chamber of $75 \mathrm{ml}$. The mixing procedure employed was first plasticizing the E-SBR for one minute before the $5 \mathrm{phr}$ of $\mathrm{ZnO}$ and $1 \mathrm{phr}$ of stearic acid were added. The total mixing time was $5 \mathrm{~min}$, and the temperature in the chamber did not exceed $50{ }^{\circ} \mathrm{C}$. The first mixing step was immediately followed by the second step, carried out on a David Bridge (UK) two-roll open mixing mill. After 1 min of mixing on the two-roll mill, the accelerators were added, and after another $3 \mathrm{~min}$, the rhombic sulfur was incorporated. The compounds were homogenized for $10 \mathrm{~min}$ while the temperature of the compounds did not exceed $40^{\circ} \mathrm{C}$. The reference sample (Ref.) was prepared following the same procedure, without addition of any curatives in the second step. The composition of the series was planned in such a way that according to the classification based on the phr unit, shown in Table I, the $\mathrm{TMTD} / \mathrm{S}_{8}$ series belongs to the $\mathrm{CV}$, whereas the $\mathrm{ZDT} / \mathrm{S}_{8}$ series to the $\mathrm{SEV}$ curing systems. The compositions of the mixtures, where the amounts of the curatives are expressed both in phr and in moles, are given in Table III. The number of the accelerators' moles was calculated for the content of the pure active chemical substance in the commercially available curatives, as listed in Table II. 


\section{TABLE III}

COMPOSITION OF THE STUDIED SAMPLES IN “PHR” AND “MMOL”, GIVEN FOR 100 PHR OF E-SBR, 5 PHR OF ZINC OXIDE AND 1 PHR OF STEARIC ACID

\begin{tabular}{|c|c|c|c|c|c|c|}
\hline Sample & Unit & \multicolumn{5}{|c|}{ Amount of curatives (accelerator/sulfur) } \\
\hline \multirow{2}{*}{ Ref. } & phr & \multicolumn{5}{|c|}{$0.00 / 0.00$} \\
\hline & mmol & \multicolumn{5}{|c|}{$0.00 / 0.00$} \\
\hline \multirow{2}{*}{ TMTD $/ \mathrm{S}_{8}$} & phr & $0.25 / 0.90$ & $0.36 / 1.30$ & $0.50 / 1.79$ & $0.70 / 2.50$ & $1.00 / 3.58$ \\
\hline & mmol & $1.00 / 3.50$ & $1.40 / 5.10$ & $2.00 / 7.00$ & $2.80 / 9.70$ & $4.00 / 14.00$ \\
\hline \multirow{2}{*}{$\mathrm{ZDT} / \mathrm{S}_{8}$} & phr & $1.50 / 1.50$ & $2.20 / 2.20$ & $3.00 / 3.00$ & $5.00 / 5.00$ & $6.50 / 6.50$ \\
\hline & mmol & $1.00 / 5.80$ & $1.40 / 8.60$ & $1.90 / 11.70$ & $3.20 / 19.50$ & $4.20 / 25.30$ \\
\hline
\end{tabular}

Curing. - After addition of the curing agents, the compounds curing properties were determined with an RPA2000 rubber process analyzer from Alpha Technologies (USA). The increase in torque at $160{ }^{\circ} \mathrm{C}, 0.833 \mathrm{~Hz}$ and $2.79 \%$ strain was measured over a time period of $60 \mathrm{~min}$. The optimal cure time $\left(\tau_{95}\right)$ of the compounds was determined. $100 \times 100 \times 2 \mathrm{~mm}^{3}$ rubber sheets were cured in an electrically heated Wickert laboratory press WLP $1600 / 5^{*} 4 / 3$ (Germany) at $160{ }^{\circ} \mathrm{C}$ and 100 bar for the optimal cure time. The uncrosslinked reference (Ref.) was prepared by compression molding at a temperature of $160^{\circ} \mathrm{C}$ for $10 \mathrm{~min}$.

\section{EXTRACTION WITH ACETONE}

The extraction with acetone served to remove low molecular non-rubber soluble substances, such as zinc salt of the accelerator and its decomposition products, zinc fatty acid soaps, antioxidants, polymerization aids, etc. ${ }^{15}$ The cured samples were extracted with acetone in a Soxhlet apparatus for 72 hrs. This was followed by leaving the samples at room temperature for $6 \mathrm{hrs}$, and then drying them to a constant weight at $55^{\circ} \mathrm{C}$ in a Heraeus (Germany) oven with an air circulation system. The acetone-extracted samples were used for crosslink density analysis, DSC glass transition and TGA thermo-oxidative stability studies.

\section{CROSSLINK DENSITY ANALYSIS}

To analyse the crosslink density, samples of approx. $0.05 \mathrm{~g}$ were swollen to equilibrium in toluene for 4 days at room temperature $\left(23{ }^{\circ} \mathrm{C} \pm 1{ }^{\circ} \mathrm{C}\right)$. This was followed by drying the samples to a constant weight for 4 days 
at $60{ }^{\circ} \mathrm{C}$ in a Heraeus (Germany) oven with an air circulation system. The crosslink density was calculated on the basis of the Flory-Rehner equation ${ }^{32}$ :

$$
v=-\frac{\ln \left(1-V_{r}\right)+V_{r}+\chi V_{r}^{2}}{V_{0}\left(V_{r}^{\frac{1}{3}}-\frac{2 V_{r}}{f}\right)}
$$

where:

$v$ - crosslink density per unit volume $\left[\mathrm{mol} / \mathrm{cm}^{3}\right]$;

$V_{r}$ - volume fraction of rubber in a swollen sample [-];

$V_{0}-$ solvent molar volume (for toluene: $V_{0}=106.9 \mathrm{~cm}^{3} / \mathrm{mol}$ );

$f$ - functionality of crosslinks ( $f=4$, assuming the formation of tetra-functional crosslinks);

$\chi$-Flory-Huggins rubber-solvent interaction parameter (for the SBR-toluene system: $\chi=0.378^{34}$ ).

The given crosslink density values are the average of four specimens of every sample. The relative standard deviation is approx. $3.0 \%$ on average.

\section{CROSSLINK STRUCTURE ANALYSIS}

The structure of the crosslinks was determined by thiol-amine analysis. ${ }^{28}$ It is based on a selective cleavage of particular types of sulfidic crosslinks by two sets of thiol-amine chemical probes. In the literature ${ }^{28}$ it is described that the polysulfidic crosslinks should be cleaved by the "soft" probe, composed of 2-propanethiol $(0.4 \mathrm{M})$ and piperidine $(0.4 \mathrm{M})$ in toluene. This analysis was run for $2 \mathrm{hrs}$ under nitrogen gas atmosphere in a closed glass vial, using rubber samples pre-swollen in toluene for $12 \mathrm{hrs}$. The polysulfidic and disulfidic crosslinks should be cleaved by the "hard" probe, which composition was 1-dodecanethiol (1.0 M) in piperidine. This analysis was run for $24 \mathrm{hrs}$ under nitrogen gas atmosphere in a closed glass vial. After the thiol-amine analyses, the samples were removed from the probes immediately. The probe residues were removed from the samples by washing them at least five times with toluene for $30 \mathrm{~min}$ at room temperature. After this, the remaining crosslink density was analyzed by equilibrium swelling in toluene and calculated on the basis of the Flory-Rehner equation ${ }^{32}$ (according to the procedure described in the Section "Crosslink density analysis"). 


\section{DIFFERENTIAL SCANNING CALORIMETRY (DSC)}

Differential Scanning Calorimetry (DSC) measurements were performed with use of a DSC Polyma 214 calorimeter from Netzsch-Gerätebau (Germany). The samples of approx. $10 \mathrm{mg}$ were placed in standard aluminium pans with pierced lids. The measurements were carried out in nitrogen atmosphere as follows: (i) cooled at a rate of $10{ }^{\circ} \mathrm{C} / \mathrm{min}$ from $30{ }^{\circ} \mathrm{C}$ to $-110{ }^{\circ} \mathrm{C}$; (ii) stabilized at $-110{ }^{\circ} \mathrm{C}$ for $3 \mathrm{~min}$; and (iii) heated at a rate of $10{ }^{\circ} \mathrm{C} / \mathrm{min}$ from $-110{ }^{\circ} \mathrm{C}$ to $30^{\circ} \mathrm{C}$. Prior extraction of the samples with acetone served to obtain smoother thermograms, without influencing the $T_{g}$ values. A thermal history effect was checked by recording three measurement cycles for a representative set of samples. The same $T_{g}$ values were obtained, which showed that the measurements were not sensitive to thermal history. The data shown here were therefore collected during the first heating scan. The values of glass transition temperature were taken from the midpoints of the heat capacity change during the heating step.

\section{DYNAMIC MECHANICAL ANALYSIS (DMA)}

Dynamic mechanical measurements were performed with use of a dynamic-mechanical analyser DMA Viscoanalyseur VA2000 from Metravib (France), operating in tension mode. The test frequency was fixed at $10 \mathrm{~Hz}$, and the strain at $0.1 \%$, which was within the linear viscoelastic region of the studied samples. The dimensions of the test bar specimens were $40 \times 5 \times 2 \mathrm{~mm}^{3}$. The data were evaluated by Dynatest 6.83 software. The measurements were carried out with a temperature sweep in the range of $-80{ }^{\circ} \mathrm{C}$ to $80{ }^{\circ} \mathrm{C}$. In the temperature range of the loss modulus $\left(E^{\prime \prime}\right)$ and tan delta $(\tan \delta)$ changes, the temperature interval was $1{ }^{\circ} \mathrm{C}$. This allowed establishing an accurate determination of the $T_{g}$ values. In the rest of the measurement, the interval was $5{ }^{\circ} \mathrm{C}$. The initial stabilization time at $-80^{\circ} \mathrm{C}$ was set to $15 \mathrm{~min}$, whereas for other measurement points it was 3 min.

\section{BUOYANCY METHOD}

To determine the density of the uncrosslinked reference and the cured samples, a buoyancy method was used. The measurements were carried out in ethanol at a temperature of $23{ }^{\circ} \mathrm{C}$. Analytical balance Radwag (Poland), equipped with a standard kit for density determination, was used. The given density is an average of six measurements. The relative standard deviation of the experiment was approx. $1 \%$. 


\section{POSITRON ANNIHILATION LIFETIME SPECTROSCOPY (PALS)}

The measurements of the positron lifetime spectra of the samples were performed using a fastfast positron lifetime spectrometer with $\mathrm{BaF}_{2}$ scintillators. The time resolution (FWHM) of the lifetime spectrometer was approx. 250 ps. The positron source, ${ }^{22} \mathrm{Na}$ enveloped in $7 \mu \mathrm{m}$ kapton foil, was located between the surfaces of two identical samples. This sandwich was positioned in front of the scintillation detectors of the spectrometer. The positron lifetime spectra were measured for 24 hrs to obtain more than $2 \times 10^{6}$ counts in the spectrum. Deconvolution of each spectrum was performed assuming three lifetime components. This was sufficient to obtain a satisfactory $\chi^{2}$ value close to unity. The source component was also taken into account during the deconvolution procedure. The free volume size was calculated taking advantage of the longest (about 2 ns) lifetime component in the PALS spectrum, on the basis of the Tao-Eldrup semi-empirical equation ${ }^{35,36}$. In the calculation, the spherical shape of the free volume was assumed. The PALS analysis was performed for four samples of each series. The error bar of the free volume radius is expressed as the standard deviation of the measurement.

\section{THERMOGRAVIMETRIC ANALYSIS (TGA)}

Thermogravimetric analyses were carried out with use of TGA 4000 analyzer from Perkin Elmer (USA). Samples of approx. $8 \mathrm{mg}$, placed in ceramic pans, were heated from $30{ }^{\circ} \mathrm{C}$ to $700{ }^{\circ} \mathrm{C}$ with a rate of $10^{\circ} \mathrm{C} / \mathrm{min}$. The analysis was conducted in synthetic air. Prior extraction with acetone served to remove soluble substances, not attached to the polymer network, which could have a profound effect on the thermal analysis. ${ }^{15}$ The thermo-oxidative stability of the samples was characterized in terms of the onset of degradation temperature $\left(T_{0}\right)$ and the highest degradation rate temperature $\left(T_{h}\right)$.

\section{MECHANICAL PROPERTIES}

Tensile strength tests were carried out with use of Zwick Roell type BZ1.0/TH1S universal tensile testing machine with extensometers from Zwick Roell (Germany). The test specimens were dumbbells type 3 (ISO 37), tested at a constant crosshead speed of $500 \mathrm{~mm} / \mathrm{min}$ at a temperature of $23 \pm 1{ }^{\circ} \mathrm{C}$. Seven dumbbell specimens were tested for each sample and the average is reported here. The error bars of the tensile strength $(T S)$ and elongation at break $\left(E_{b}\right)$ values are expressed as the standard deviation of the measurement. 


\section{RESULTS AND DISCUSSION}

\section{CROSSLINK DENSITY AND CROSSLINK STRUCTURES}

In both studied series, an increasing amount of the curatives resulted in the formation of a higher crosslink density, as shown in Figure 3. This is caused by more transformation products of the curatives, which were involved in the curing process. In two investigated series, the number of the accelerator moles was kept on similar level, as listen in Table III. At the same time, the sulfur level was lower in TMTD/S $\mathrm{S}_{8}$ series. Due to that, sulfur was used for crosslinking more efficiently in $\mathrm{TMTD} / \mathrm{S}_{8}$ samples, comparing to further possible side reactions.

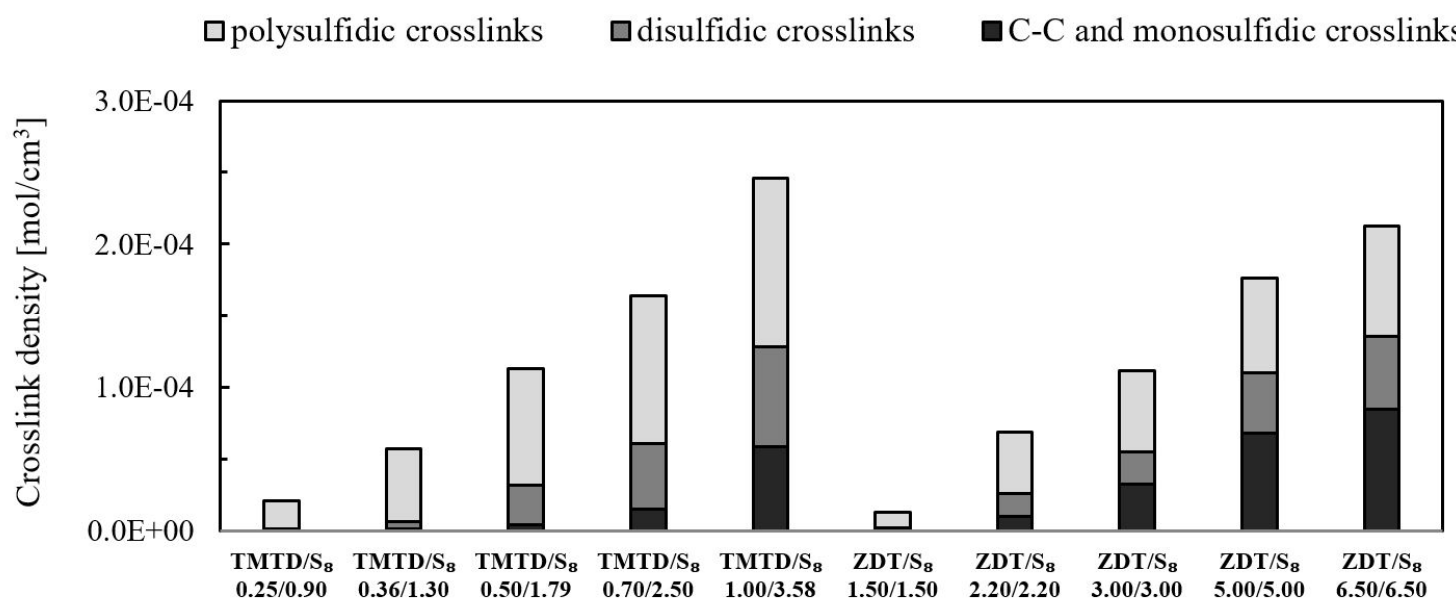

FIG. 3. - Crosslink density and crosslink structures formed during the curing process. The columns are particular samples in the two studied series, as listed in Table III (amounts of curatives expressed in phr).

During the curing process, various types of crosslinks were developed. In the TMTD/S $\mathrm{S}_{8}$ samples, the long polysulfidic crosslinks pose the major type, followed by the medium length disulfidic crosslinks. The shorter C-C and monosulfidic crosslinks were also formed. The ZDT/S $\mathrm{S}_{8}$ samples have a slightly higher participation of $\mathrm{C}-\mathrm{C}$ and monosulfidic crosslinks, at the expanse of the di- and poly- sulfidic crosslinks. Nevertheless, the crosslink structures are not very different in the two studied series.

When the amount of the curatives is expressed in phr unit, the ratio between the accelerator and sulfur in $\mathrm{ZDT} / \mathrm{S}_{8}$ samples is 1 (Table IV). When the molecular weights of the ZDT and sulfur are considered, and their amount is calculated in moles, this ratio is as low as 0.17 . This means that the number of the ZDT molecules incorporated into the system, which could react upon curing, was in a very small amount in relation to the molecules of rhombic sulfur. For the TMTD/S $\mathrm{S}_{8}$ samples, the ratio between the accelerator and sulfur expressed 
in phr is 0.28 . When the amount of TMTD and sulfur is calculated in moles, the ratio between them equals to 0.29. The number of the TMTD molecules reacting with sulfur is therefore slightly higher than the corresponding number of ZDT molecules.

TABLE IV

DEPENDENCE BETWEEN THE AMOUNT OF THE ACCELERATORS AND SULFUR

\begin{tabular}{|c|c|c|}
\hline Sample & Ratio (calculated in phr) * & Ratio (calculated in moles) $* *$ \\
\hline TMTD $/ \mathrm{S}_{8}$ & 0.28 & 0.29 \\
\hline $\mathrm{ZDT} / \mathrm{S}_{8}$ & 1.00 & 0.17 \\
\hline
\end{tabular}

* The ratio was calculated as: (phr number of accelerator)/(phr number of rhombic sulfur).

** The ratio was calculated as: (moles of accelerator)/(moles of rhombic sulfur).

As the two studied series of samples show, the classical description of the curatives' amount in phr is insufficient. In fact, phr is a simplified unit, which serves to easily calculate the amount of various additives in a mixture formulation on a weight basis. Due to its universality, it was widely accepted by rubber technologists and research scientists. However, the phr unit does not consider the molecular weight of the curatives, i.e. the number of the reacting molecules. As a result, the phr unit can be misleading. This is particularly important in case of curing accelerators, which can have very diversified structures, such as TMTD and ZDT. To overcome this problem, the amount of the curatives should be expressed in mol unit. In this way, the number of reacting molecules is clearly expressed.

Furthermore, the classification of the accelerated sulfur curing systems as conventional, semi-efficient and efficient systems is also based on the phr unit. However, when the amount of the curatives is calculated in moles, the ratio between the curatives can differ significantly to the description in phr units. Due to that, the classification in this form should be used with great caution. Instead, the number of the reacting molecules of accelerator and sulfur should be considered, as indicated by their amounts in moles. Based on this insight a new classification of the curing system is proposed and presented in Table V. 
TABLE V

NEW PROPOSED CLASSIFICATION OF THE CURING SYSTEMS, BASED ON THE RATIO BETWEEN THE ACCELERATOR AND SULFUR, CALCULATED IN MMOL

\begin{tabular}{cccc}
\hline Curing system & Amount of & Amount of sulfur**, & Accelerator to sulfur \\
& accelerator***, mmol & mmol & ratio $^{*},-$ \\
\hline Conventional (CV) & $1.4-4.6$ & $6.6-13.6$ & $0.1-0.7$ \\
Semi-efficient (SEV) & $4.6-9.8$ & $3.9-6.6$ & $0.7-2.5$ \\
Efficient (EV) & $7.8-19.2$ & $1.6-3.1$ & $2.5-12.0$ \\
\hline
\end{tabular}

* The ratio between the accelerator and sulfur was retrieved from Table 1.

** The amount of sulfur was retrieved from Table 1 and converted from phr into moles as: (mass of rhombic sulfur)/(molecular weight of rhombic sulfur).

*** The amount of accelerator in moles was calculated as: (moles of rhombic sulfur) $\times($ accelerator to sulfur ratio).

According to the classification based on the phr unit, the TMTD/S $\mathrm{S}_{8}$ series belongs to the $\mathrm{CV}$, whereas the $\mathrm{ZDT} / \mathrm{S}_{8}$ series to the SEV curing systems. When applying the new classification, which considers the molecular weight and moles number of the curatives, both of the series fall into the CV category. The crosslink structure is dependent on the ratio between the curatives. This structural parameter shows no large differences between the $\mathrm{TMTD} / \mathrm{S}_{8}$ and $\mathrm{ZDT} / \mathrm{S}_{8}$ series. This is the first indication that this new concept is advantageous, comparing to the traditionally used one.

\section{EFFECT OF CURING ON THE GLASS TRANSITION TEMPERATURE}

Glass transition temperature determined by Differential Scanning Calorimetry. - During the glass transition process, molecular motions of the polymer segments begin. As a result, in a range of temperatures associated with this process, many of the polymer properties exhibit abrupt changes. These changes can be used to "locate" the glass transition process on a temperature scale. As a simplification ${ }^{37,38}$, the process is ascribed to one particular value of temperature, mainly glass transition temperature $\left(T_{g}\right)$, and in this form is reported in literature. One of the changes during the glass transition process is the heat capacity. The DSC technique is customarily used to monitor it. Determined in this way, $T_{g}$ is sometimes referred to as "calorimetric", or due to 
the fact that during this measurement the sample is not exposed to external deformations it is called "static". In the following description, the term "static" $T_{g}$ will be used.

As Figure 4 shows, the "static" $T_{g}$ of the uncrosslinked reference of the E-SBR (Ref.) is approx. $-53{ }^{\circ} \mathrm{C}$. Since the reference has no chemical crosslinks and the polymer chains interact with each other via weak van der Waals forces, the value of $T_{g}$ comes from the microstructure of E-SBR. As a result of curing, the $T_{g}$ of the samples increases. The rise in crosslink density is followed by a linear increase in $T_{g}$, for both investigated series. The formed crosslinks are strong covalent bonds, which unite the polymer chains and hinder their segmental mobility. As a result, the material becomes more compact and stiffer. The increase in $T_{g}$ is due to higher thermal energy required to enable molecular mobility of the polymer segments. Actually, it is a well-known phenomenon ${ }^{39,40}$ that the presence of crosslinks causes an increase in the glass transition temperature.

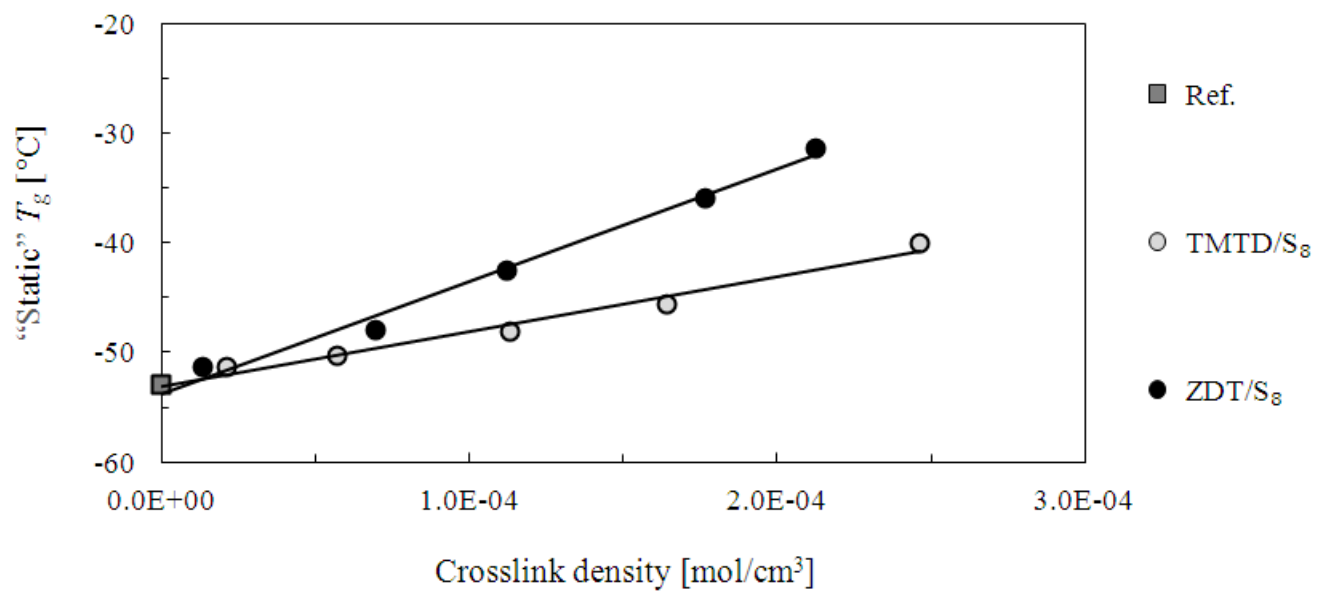

FIG. 4. - "Static" $T_{g}$ as a function of crosslink density for the uncrosslinked reference and cured samples.

The dependences for the two series studied vary significantly: the increment for the $\mathrm{ZDT} / \mathrm{S}_{8}$ is much larger than for the $\mathrm{TMTD} / \mathrm{S}_{8}$. This shows that beside the crosslink density there are other structural parameters of cured elastomers, which influence their $T_{g}$ value.

Crosslink density is the most crucial parameter, which influences the behavior of elastomers. It is generally accepted that the crosslink structure is the second most important parameter. In the two studied series of samples the crosslink structure shows no large difference. However, also in this case the behavior of the polymer chains can be different. Therefore, it must be another structural parameter, which has a large impact on the properties. 
As Mason $^{41}$ predicted, simple crosslinking increases the $T_{g}$ value only to a low extent. Chan ${ }^{15}$ suggested that of greater importance is the amount of the modifications of the chains. During the curing process, not all of the curatives were consumed in the reactions leading to intermolecular crosslinks formation. Instead, part of the accelerators' fragmentation products and sulfur chains can be chemically attached to only one polymer chain. In this way, they create elastically ineffective modifications of the chains. They restrict the free rotation of the polymer segments and stiffened the chains. ${ }^{15}$ The difference between the $T_{g}$ values of the two series studied shows that the type of curatives influenced the behaviour of the polymer chains. The two studied series of samples contain different accelerators. TMTD is a molecule of a low molecular weight of $240.43 \mathrm{~g} / \mathrm{mol}$ and is small in size. In contrast, ZDT has a high molecular weight of $772.47 \mathrm{~g} / \mathrm{mol}$, which is over 3 times larger than that of TMTD. ZDT shows a complex structure, with bulky 2-ethylhexyl substituents and polar dithiophosphate groups. The degree to which the modification of the chains influences the hindrance of the free rotation is dependent on its size, bulkiness and structure. The larger and bulkier the moieties of the accelerator are, the stronger the effect of the hindrance and the stiffening of the polymer chains are. As a result, the $T_{g}$ increases. TMTD, due to its small size, probably did not stiffen the polymer chains significantly, so they remained more flexible and mobile. At the same time, the ZDT caused much larger increase in $T_{g}$ value. Curing with ZDT led to the formation of bulky side groups, which require high thermal energy to enable molecular mobility and undergo the glass transition process. Furthermore, ZDT is a polar molecule and has a large dipole moment, which also possibly contributed to this rise. The ZDT fragments bound to the chains could interact with other similar fragments via strong association, and act as labile crosslinks. ${ }^{7,15}$ This additionally restricted the mobility of the polymer chains. Beside the accelerator, also sulfur can create modifications, in a form of cyclic sulfidic structures. They could additionally contribute to the stiffening of the chains and increase in $T_{g}$ value. Due to a slightly higher amount of sulfur in the $\mathrm{ZDT} / \mathrm{S}_{8}$ series, it is probable that the number of the cyclic sulfidic structures is higher in this series of samples. All the formed modifications pose rotational restriction of the polymer chains. They cause a considerable decrease in the mobility of the chains, especially in vinyl polymers ${ }^{42}$, such as E-SBR.

The presented results dispute the findings of Campbell. ${ }^{11}$ He suggested that in a CV curing system, the pendant groups are unlikely to make a significant contribution to the physical properties of the material. His deduction was based on the analysis of the quite low concentration of the pendant groups, and respectively higher concentration of the cyclic sulfidic structures. However, he investigated systems cured with use of only one type of accelerator: N-cyclohexylbenzothiazole-2-sulfenamide (CBS). In the present work, two various 
accelerators were used and the results are re-evaluated, considering additionally the contribution of the accelerator structure. The results indicate that even in the case of CV curing systems, the influence of this type of modifications on the behavior of the polymer chains can be large. The degree of this influence is strongly dependent on the size of the accelerator molecule - small molecules neither stiffen the polymer chains nor hinder their mobility. The large molecules, however, can significantly restrict the molecular dynamics of the chains, as detected by an increase in the $T_{g}$ value.

Glass transition process monitored by Dynamic Mechanical Analysis. - In a DMA measurement, during the glass transition process the molecular mobility begins at a particular temperature in response to externally applied deformations at a particular frequency. As a result, segments of the chains undergo conformational rearrangements to minimize localized stress, as it is possible on an experimental time scale. DMA tests were performed to study microscale changes in molecular mobility and dynamics. Since those changes follow externally applied mechanical deformations of the samples, the $T_{g}$ values determined from the DMA measurement are referred to as the "dynamic" $T_{g}$. This stays in contrast with the "static" $T_{g}$ obtained from the DSC measurements, in which the samples were not deformed during the test. The "dynamic" $T_{g}$ values were determined by the temperature of the loss modulus $\left(E^{\prime \prime}\right)$ and the tan delta $(\tan \delta)$ peak maxima. The changes in the "dynamic" $T_{g}$ values are shown in Figure 5.

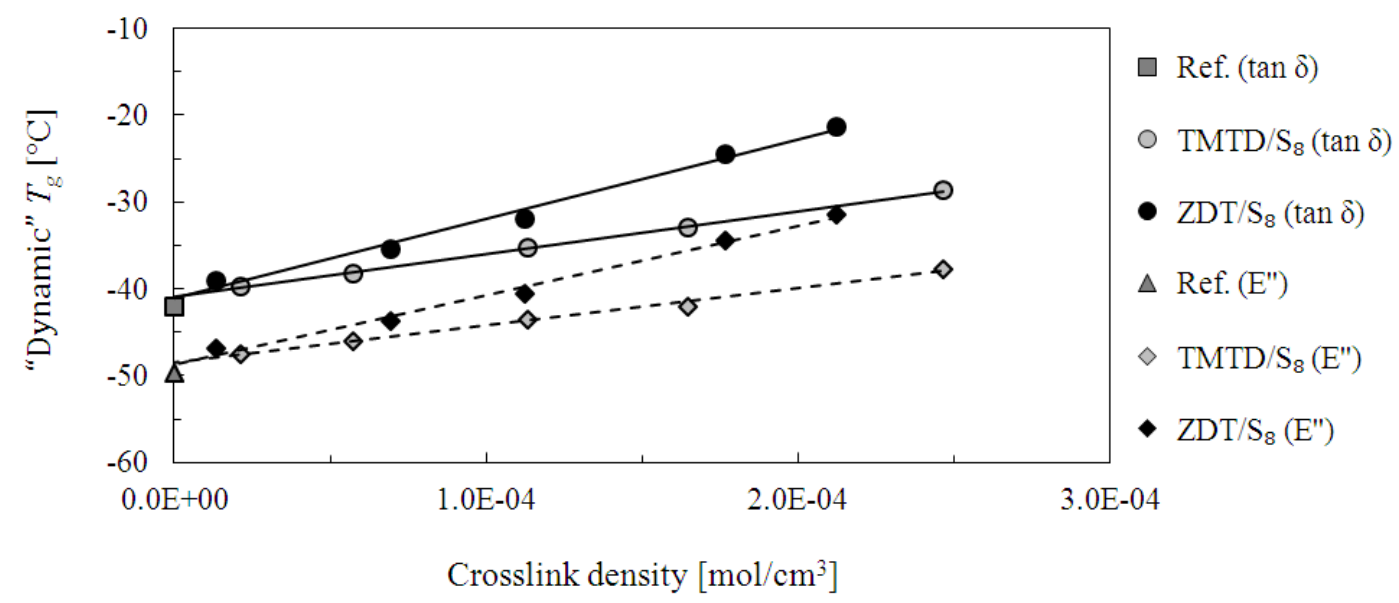

FIG. 5. - "Dynamic" $T_{g}$, determined by a maximum of peaks of the $\tan \delta$ (solid line) and $E$ "' (dashed line), as a function of crosslink density for the uncrosslinked reference and cured series of samples.

The "dynamic" $T_{g}$ of the uncured reference, evaluated by the $E$ "' maximum is approx. $-50{ }^{\circ} \mathrm{C}$, whereas determined by the $\tan \delta$ it is approx. $-42{ }^{\circ} \mathrm{C}$. These temperature values differ from the "static" $T_{g}$ (approx. -53 
${ }^{\circ} \mathrm{C}$ ), due to different changes in the properties studied with the techniques used. In a DSC measurement, the sample was static, whereas in a DMA measurement, it was deformed with the frequency of $10 \mathrm{~Hz}$. At this frequency, the time for molecular rearrangements and relaxation was shorter than in the static DSC measurement. Due to that, the values of the "dynamic" $T_{g}$ are increased, comparing to the $T_{g}$ obtained from the static measurement.

For the cured samples, the "dynamic" $T_{g}$, determined both by the $\tan \delta$ and $E$ ", shifts to higher temperatures with an increase in the crosslink density. This corresponds to changes already observed in case of the "static" $T_{g}$. The increase is significantly larger for $\mathrm{ZDT} / \mathrm{S}_{8}$ than for TMTD/S $\mathrm{S}_{8}$ cured samples. For the samples of the same composition, the differences between the maxima of the corresponding $\tan \delta$ and $E^{\prime \prime}$ peaks are within the range of $8-11^{\circ} \mathrm{C}$.

The damping properties at elevated temperature, i.e., $70{ }^{\circ} \mathrm{C}$, were evaluated by determination of the $\tan \delta$. Figure 6 presents these values, correlated with the crosslink density. The dependence shows that the uncrosslinked reference has the highest $\tan \delta$ value at $70{ }^{\circ} \mathrm{C}$, approx. 0.38 . An increase in the crosslink density resulted in a large reduction of damping. This is due to an increase in the number of crosslinks, which provide elastic response and lower dissipation of energy for both investigated series. The value of the $\tan \delta$ at elevated temperature is strongly dependent on the total crosslink density. There is no clearly visible difference in damping behavior between the samples cured with the two accelerated sulfur curing systems used in this experiment. The crosslink structures in the two series of samples are not very different. Therefore, on the basis of these results it is not possible to evaluate whether the crosslink types influence the $\tan \delta$ values. However, according to literature $^{43-44}$ and own previous studies ${ }^{45}$, the crosslink types do not influence damping. Furthermore, the effect of various modifications of the chains formed in $\mathrm{TMTD} / \mathrm{S}_{8}$ and $\mathrm{ZDT} / \mathrm{S}_{8}$ series is not visible. This is probably due to the fact that these modifications do not influence damping considerably, or that the DMA technique is not precise and sensitive enough to "detect" such small changes. 


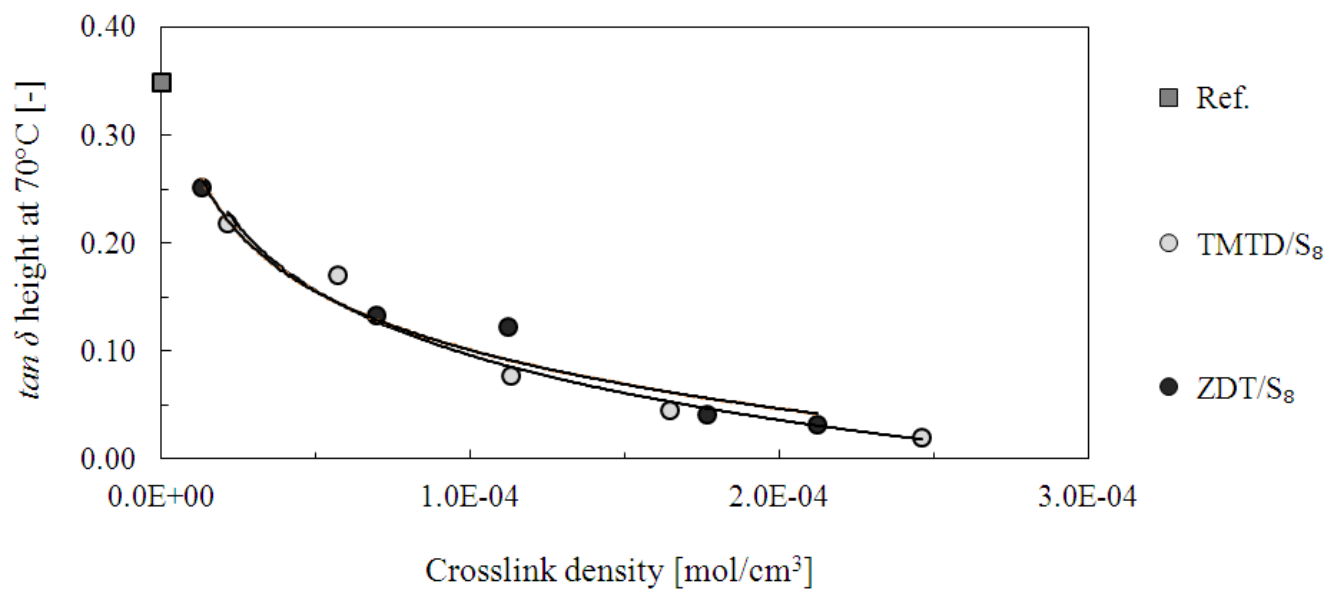

FIG. 6. - Dependence between height of $\tan \delta$ at $70{ }^{\circ} \mathrm{C}$ and crosslink density for the uncrosslinked reference and cured series of samples.

\section{EFFECT OF CURING ON THE MOLECULAR STRUCTURE AND PACKING OF THE POLYMER CHAINS}

Free volume size determined by Positron Annihilation Lifetime Spectroscopy. - The free volume is associated with the space (voids) between molecules in a particular material. The size of free volumes is usually studied with use of Positron Annihilation Lifetime Spectroscopy (PALS). In the context of PALS technique, the free volume is considered as an area of significantly decreased electron density, surrounded by polymer chains, crosslinks and modifications. It is, therefore, dependent on the microstructure of the polymer chains and structural features formed by the curatives. The PALS technique is based on the relation between the free volume size and the lifetime of the longest lifetime component in the PALS spectrum. Room-temperature PALS measurements were carried out to evaluate how the network parameters of the cured elastomers influence the average free volume size. Figure 7 shows changes in the free volume size, expressed by its radius, as a function of crosslink density. 


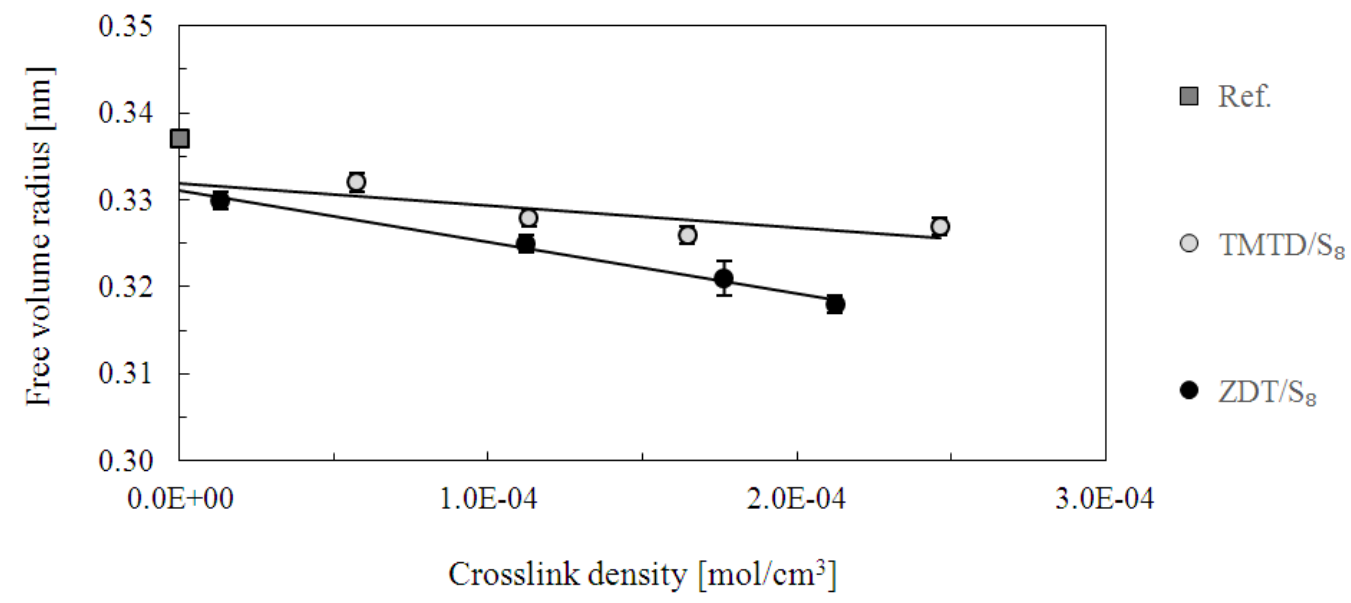

FIG. 7. - The free volume radius as a function of crosslink density for the uncrosslinked reference and cured series of samples.

The size of free volume is the largest for the uncrosslinked reference. For cured samples, the average free volume size decreased when the crosslink density rose. It is known from literature ${ }^{45-51}$ that crosslinks reduce the size of the unoccupied area between polymer chains. The denser the network is, the smaller the free volumes are. However, the present results show that the degree of this change differs for samples crosslinked with various curatives. The decrease in the free volume radius is larger for ZDT/ $\mathrm{S}_{8}$ than for TMTD/ $\mathrm{S}_{8}$ cured samples - it is dependent on the type of curatives used. Mallon et al. ${ }^{47}$ noticed a similar dependence of the free volume size on the type of curatives, such as dicumyl peroxide (DCP), tetramethylthiuram disulfide with sulfur (TMTD/S ${ }_{8}$ ) and 2,2'-dibenzothiazyl disulfide with sulfur $\left(\mathrm{MBTS}_{\mathrm{S}} \mathrm{S}_{8}\right)$.

In the samples studied, there are mainly long polysulfidic and medium length disulfidic crosslinks. With regard to that, it would be expected that the free volume size remains large. However, it decreased: this reduction is probably caused by intramolecular modifications formed by the curatives, which are grafted on the chains. They could fill in the free volumes, i.e. decrease their size. In ZDT/S $\mathrm{S}_{8}$ samples, due to the larger size of the ZDT accelerator, the modifications are bulky. The cyclic sulfidic structures might also contribute to this reduction. As a result, the decrease in free volume size was larger than in case of $\mathrm{TMTD} / \mathrm{S}_{8}$ samples containing the much smaller TMTD molecules. The larger the bulkiness of the modifications are, the more expansive area they occupy. Therefore, the reduction in the free volume size is more pronounced.

The results of the DSC, DMA and PALS experiments provide complementary information. They show that the increase in the crosslink density causes a rise in $T_{g}$ values and a reduction in the free volume size. The 
results are in agreement with the general theoretical predictions ${ }^{52}$, according to which in crosslinked polymers, the increase in $T_{g}$ is followed by a decrease in free volume size. This is due to the fact that crosslinks strongly connect the polymer chains and make the material more compact. Despite the similar crosslink structure in the two series of samples studied, the changes in the $T_{g}$ and free volume size values are distinctly different. This is probably due to intramolecular modifications of the polymer chains, formed by the curatives. They contribute to a stiffening of the chains and occupy the free volumes. This is dependent on the size of the curatives, their molecular weight, size, bulkiness and stiffness. Furthermore, also other structural features of the curatives most probably contribute to the influence on the material properties. To check this, features such as structure of substituents, their steric hindrance, electronic structure, presence of particular atoms, etc. should be a subject of study in the future.

Density determined by buoyancy method. - The density of the samples cured with various curatives, measured by a buoyancy method, is presented in Figure 8 .

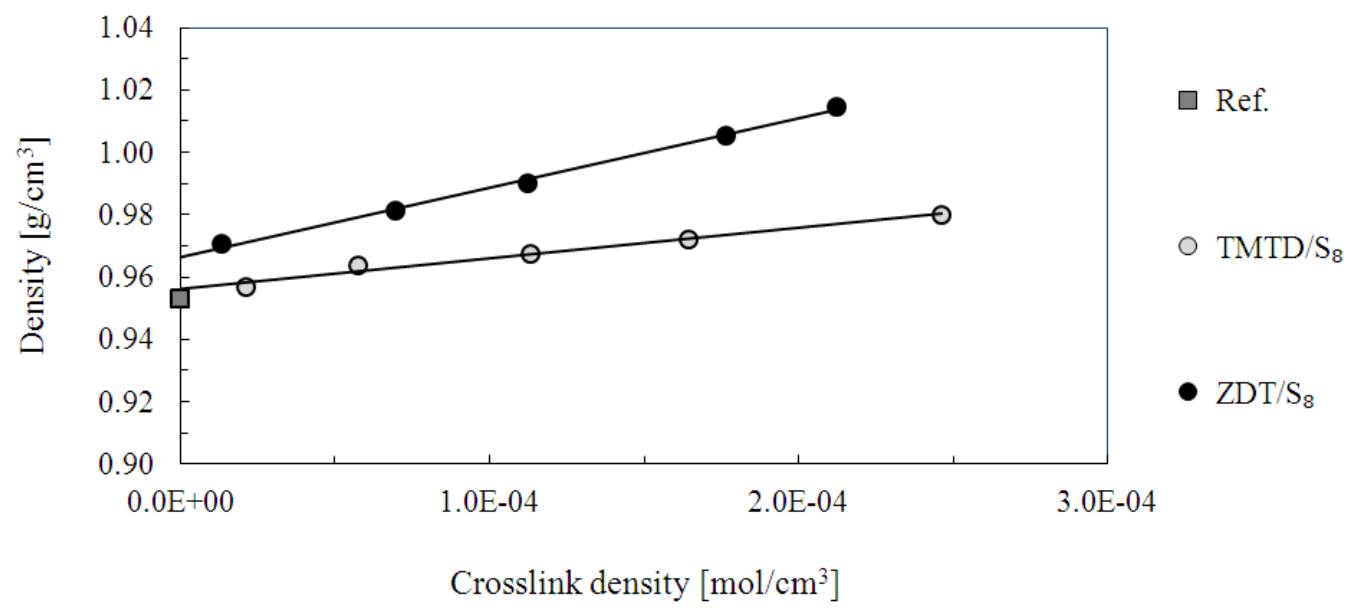

FIG. 8. - Density of samples as a function of crosslink density for the uncrosslinked reference and cured series of samples.

The uncrosslinked reference characterized itself with the lowest density. For the cured samples, the density linearly increased along with the crosslink density. For the TMTD/S $\mathrm{S}_{8}$ samples, the density values increase slightly, whereas for the $\mathrm{ZDT} / \mathrm{S}_{8}$ samples, this rise is more pronounced. The change in density is caused by (i) an addition of the curatives, which are different from the basic polymer and have their own values of density and (ii) the structural packing of the polymer chains and structures formed by the curatives. Those 
structures located and packed tightly in areas between polymer chains, as already indicated by the DSC, DMA and PALS.

\section{EFFECT OF CURING ON THE STATIC MECHANICAL PROPERTIES}

To investigate how the network parameters influence the static mechanical properties of the studied samples, tensile tests were carried out at room temperature. Figure 9 shows changes in the tensile strength (TS) as a function of the crosslink density. TS of the uncrosslinked reference is very low - approx. $0.3 \mathrm{MPa}$, which is a typical value for non-crystallizing, unfilled and uncured rubber, such as E-SBR.

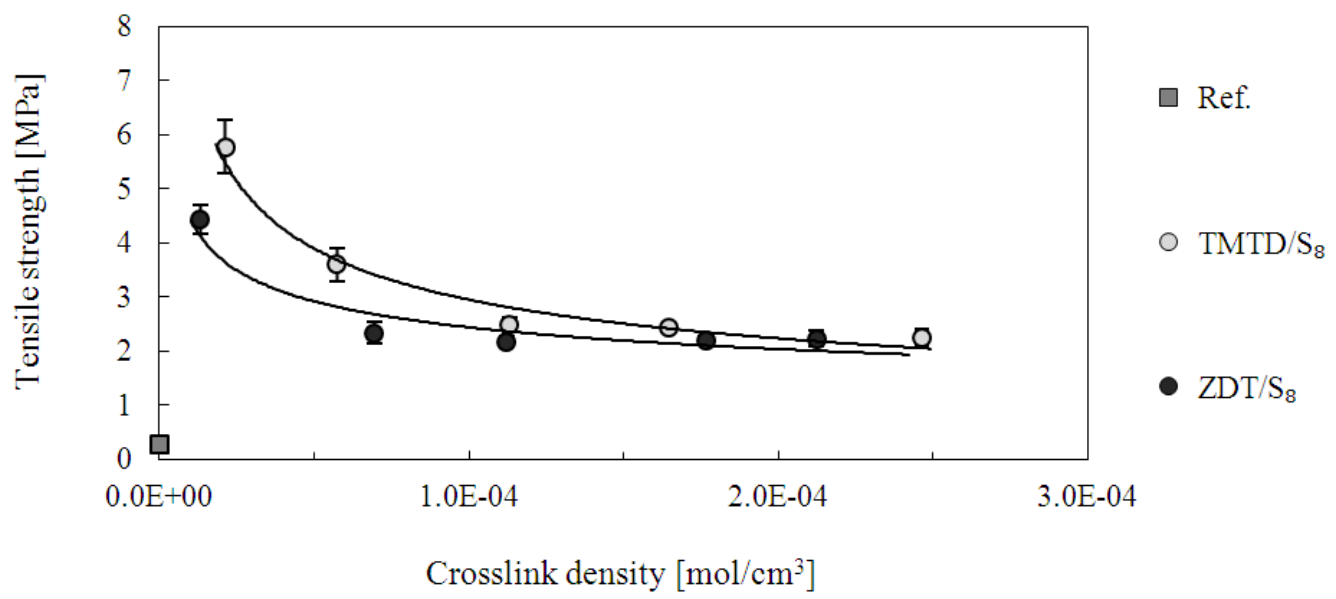

FIG. 9. - Tensile strength as a function of crosslink density for the uncrosslinked reference and cured series of samples.

As the result of curing, the strength of all the samples was improved. The highest value of the $T S$ was obtained for the samples having the lowest value of crosslink density of all cured samples, both in TMTD/S $\mathrm{S}_{8}$ and $\mathrm{ZDT} / \mathrm{S}_{8}$ series. With a further increase in the crosslink density, the $T S$ value decreased, reaching a plateau for crosslink densities larger than $1 \mathrm{E}-04 \mathrm{~mol} / \mathrm{cm}^{3}$. From literature it is known that the $T S$ values increase with increasing crosslink density, reach an optimum and decline with further rise in crosslink density. ${ }^{53}$ However, this shape of curve is characteristic for crystallizing polymers. ${ }^{54}$ As already noticed by Taylor and Darin ${ }^{54}$, in case of amorphous polymers this typical curve has a sharper maximum than in case of crystallizing polymers. Furthermore, the maximum occurs at a very low degree of crosslinking. The obtained results of $T S$ as a function of crosslink density are therefore in good agreement with the results known from literature ${ }^{54}$ for non-crystallizing 
polymers. The absolute $T S$ values of the investigated samples are low, which is typical for amorphous unfilled samples.

Since the values of $T S$ are low, the differences between the series cured with different curing systems are not large. However, it is visible that the values are slightly higher for the TMTD/S $\mathrm{S}_{8}$ series, especially in the range of low crosslink density. Since the crosslink structures are similar in both investigated series, this parameter does not explain the difference. As Table III indicates, keeping the level of the accelerator similar in both series, the amount of sulfur is higher in the $\mathrm{ZDT} / \mathrm{S}_{8}$ series than in $\mathrm{TMTD} / \mathrm{S}_{8}$ series. Therefore, it would be expected that a higher amount of sulfur in $\mathrm{ZDT} / \mathrm{S}_{8}$ series would result in larger $T S$ values of these samples. ${ }^{71,15,23,24,26,27}$ However, the obtained trend is contrary. Therefore, there should be another structural factor, which should be responsible for this difference. A possible explanation could be that the above described modifications of the polymer chains contribute to the observed variation.

In $\mathrm{ZDT} / \mathrm{S}_{8}$ series, as already discussed above, the pendant groups containing accelerator residues are bulky. Additionally, the cyclic sulfidic structures are also abundant in these samples. These modifications probably decrease the ability of sections of the chains to align as effective load-bearing chains under stress. ${ }^{17,55}$ In this way, the strength could be negatively affected, and hence lower values of $T S$ of the $\mathrm{ZDT} / \mathrm{S}_{8}$ series are observed. At the same time, the pendant groups of the TMTD accelerator are much smaller, and probably they did not affect the tensile strength in such a way that in the ZDT compounds. These results are supported by the findings of other researchers. Already in a few works ${ }^{1,7,15,17,26,27,55}$ it was suggested that the modifications can adversely affect the strength of the elastomers.

Figure 10 shows that an increase in the crosslink density is also followed by a decrease in their elongation at break $\left(E_{b}\right)$. For the uncrosslinked reference, due to unconstrained deformability of the polymer chains, the value of $E_{b}$ is as high as approx. $1600 \%$. Comparing to the reference, the curing caused a significant decrease in the $E_{b}$ values. The crosslinks restrain the deformability of the polymer chains, therefore with an increase in the crosslink density, the $E_{b}$ decreased. The differences in $E_{b}$ values for the two series of samples are within the experimental error of the tensile tests. On the basis of the obtained results it is, therefore, not possible to evaluate if the $E_{b}$ values are dependent on the type of the accelerated sulfur curing system used. 


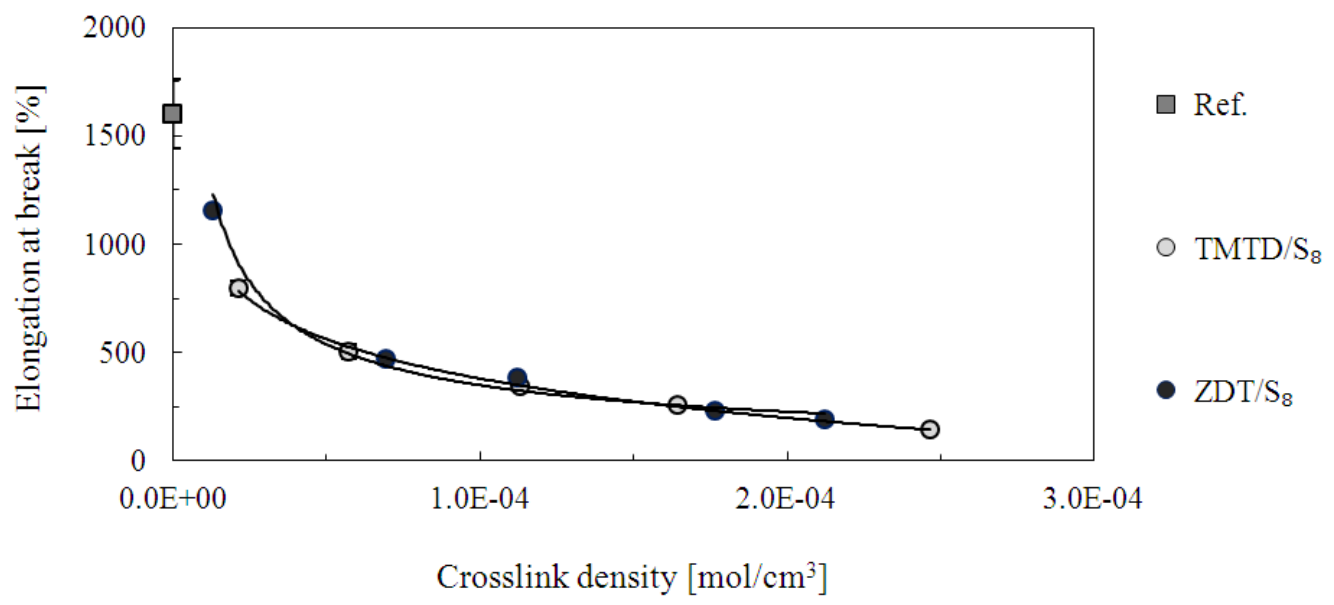

FIG. 10. - Elongation at break as a function of crosslink density for the uncrosslinked reference and cured series of samples.

\section{EFFECT OF CURING ON THE THERMO-OXIDATIVE STABILITY}

Thermal analysis was carried out to evaluate how the network parameters influence the thermooxidative stability of the samples. The analysis was conducted in synthetic air atmosphere, to mimic the most common conditions of elastomer materials use. The thermo-oxidative stability was determined by the onset of the degradation temperature $\left(T_{0}\right)$. This parameter indicates the lowest temperature at which the destructive changes in the material begin, as indicated by its weight loss. The $T_{0}$ value correlates with the crosslink density, as shown in Figure 11.

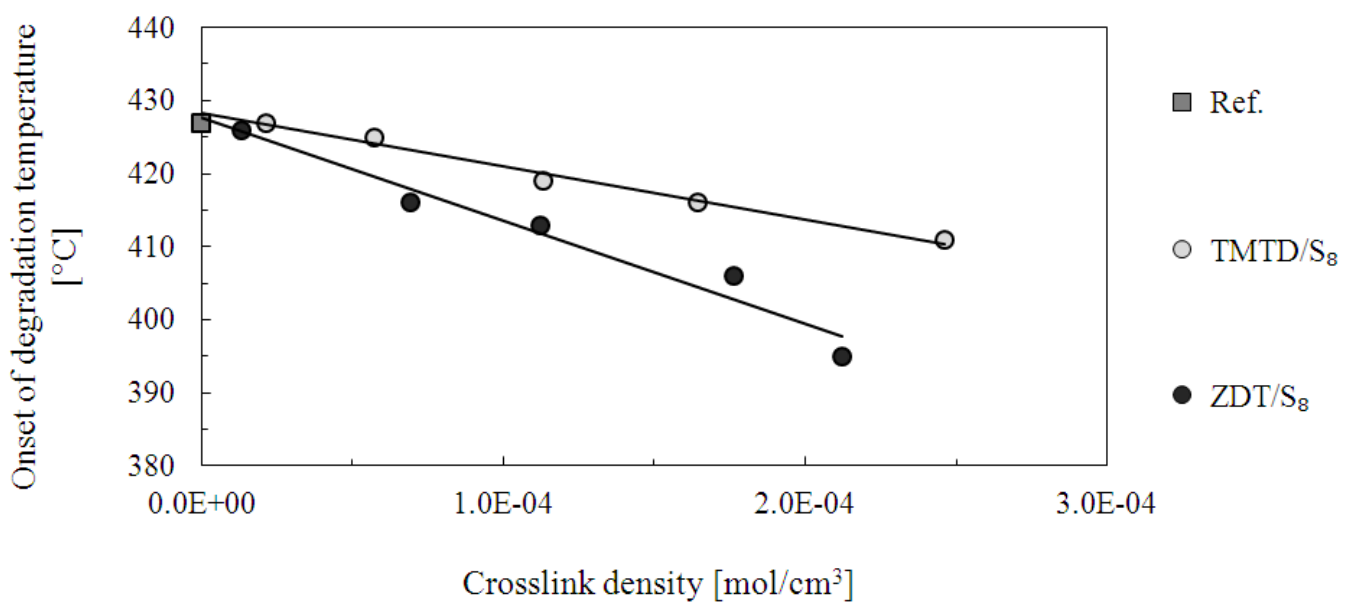

FIG. 11. - Dependence between the onset of degradation temperature and crosslink density for the uncrosslinked reference and cured series of samples. 
This dependence indicates that when the crosslink density rises, the $T_{0}$ value linearly decreases. To this decline contribute the increasing amounts of the curatives used for curing the samples with rising crosslink density. The thermal stability of elastomers cured with accelerated sulfur curing systems is in general low. This is due to the presence of polysulfidic crosslinks which have a low dissociation energy (approx. $34 \mathrm{kcal} / \mathrm{mol}$ ). ${ }^{3} \mathrm{As}$ a result, the material is susceptible to deterioration from high temperature and chemical attack of oxygen. It was already postulated that the polysulfide crosslinks, as well as sulfur combined in a form of cyclic sulfidic modifications, cause poor thermal stability. ${ }^{1,4,7,10,14,15,23,26,56}$ The polysulfidic crosslinks $\left(\mathrm{RS}_{\mathrm{x}} \mathrm{R}\right)$ and modifications of the chains in a form of pendant groups $\left(\mathrm{RS}_{\mathrm{y}} \mathrm{Acc}\right)$ show a similar structure. This suggests that the pendant groups are also susceptible to a thermo-oxidative decomposition. ${ }^{7}$ The decrease in $T_{0}$ value is much larger for the ZDT/S $\mathrm{S}_{8}$ than for TMTD/S $\mathrm{S}_{8}$ samples. Two factors possibly contribute to this. Firstly, the level of sulfur in the $\mathrm{ZDT} / \mathrm{S}_{8}$ series was slightly higher. Consequently, a greater amount of polysulfidic modifications of the chains were present in the $\mathrm{ZDT} / \mathrm{S}_{8}$ samples. Secondly, the reaction residues of some accelerators, particularly thiurams, can act as powerful antioxidants. ${ }^{15,56}$ This could give rise to higher thermo-oxidative properties of the TMTD/S 8 series.

The thermo-oxidative stability is also characterized by the temperature of the highest degradation rate $\left(T_{h}\right)$. As Figure 12 depictures, the trend is very similar to dependence of $T_{0}$ changes. For both series of samples, the $T_{h}$ decreases when the crosslink density increases. This decline is larger for the $\mathrm{ZDT} / \mathrm{S}_{8}$ than for the $\mathrm{TMTD} / \mathrm{S}_{8}$ samples.

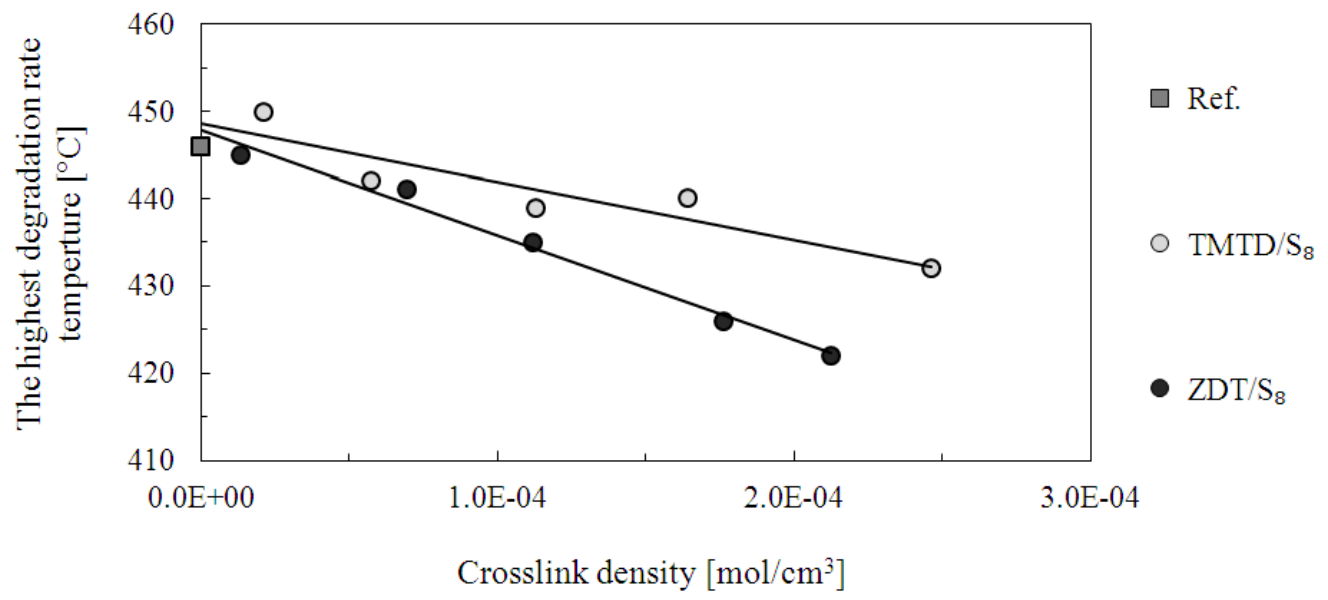

FIG. 12. - Dependence between the highest degradation rate temperature and crosslink density for the uncrosslinked reference and cured series of samples. 
The results presented in this paper, and our previous extensive studies on single-component curatives and accelerated sulfur systems ${ }^{45}$, prove that the modification of the chains play a significant role in the behavior of the polymer chains and performance of the cured material. The structure of the curatives used, i.e. accelerator, is crucial to successfully relate the microstructure of the cured elastomer with its physical and chemical properties. Not all the curatives are consumed for the production of crosslinks: they can also form non-elastic modifications of the chains. The modifications of the polymer chains seems to influence the chain stiffness, inter-chain interactions, glass transition process, ease of crystallization, relaxation times, free volume size, thermal stability, tensile strength, interaction of the chains with fillers, etc. Taking advantage of the fast development of accurate and sophisticated analytical methods, more attention should be paid to the analysis of the modifications. This would allow to provide qualitative and quantitative information on these structural features. As a result, the network structure and its influence on the properties of elastomers could be studied more profoundly.

\section{CONCLUSIONS}

From the present study, the following conclusions can be drawn:

- During the curing process, beside the formation of the intermolecular elastically effective crosslinks, also intramolecular modifications of the polymer chains are formed. This fact is often not considered in research studies. Accordingly, the crosslink density and crosslink structures, regarded as the two most important parameters, characterize the cured polymer network insufficiently. Another parameter modifications of the chains - need to be employed.

- The modifications on the polymer chains can be in a form of (i) pendant groups, such as sulfur chains terminated with accelerator fragments, and (ii) sulfidic cyclic structures. The structure of the modifications is strongly dependent on the type of the curatives and their amount. In accelerated sulfur curing systems, the structure of the accelerator is crucial: its molecular weight, size, bulkiness and stiffness of its moieties. On the basis of the curatives' structure, the influence of the modification on the behavior of the polymer chains can be predicted: the larger the size of the curatives' molecules is, the greater the stiffening of the chains occurs. Furthermore, the number of modifications increases with rise in the amount of the curatives added. 
- Both the crosslinks and the modifications, restrict the free rotation of the polymer segments. As a result, they increase the stiffness of the polymer chains and cause a rise in the $T_{g}$ values. At the same time, the modifications of the polymer chains occupy the free volumes and reduce their size. Therefore, the DSC, DMA and PALS techniques can provide information on the modifications of the polymer chains.

- Static mechanical properties and thermo-oxidative stability are influenced by the structural features of the polymer network. Formed modifications of the chains seems to have a visible influence on the investigated performance of the elastomers, as indicated by changes in values of $T S, T_{0}, T_{h}$.

- In view of the obtained results, the curatives and their structures require more attention in the elastomer research. This is especially significant due to the fact that new curatives with complex formulas and high molecular weights are constantly introduced into the market. The phr unit used to calculate their amount can be misleading. The curatives' amount should be calculated in moles - in this way, the number of curatives' molecules is clearly expressed.

\section{ACKNOWLEDGMENT}

This work was performed with support of Young Scientists' Fund at the Faculty of Chemistry, Lodz University of Technology, Grants W-3/FMN/20G/2014 and W-3/FMN/35G/2015. Sincere thanks to Apollo Tyres Global R\&D B.V. for the opportunity to conduct TGA experiments.

\section{REFERENCES}

${ }^{1}$ B. A. Dogadkin, Vulcanization of Elastomers. In Chemistry of Elastomers, 1st ed.; WNT: Warsaw, Poland, 1976; pp 201-311.

${ }^{2}$ R. N. Datta, Rubber Curing Systems. Smithers Rapra Publishing: 2001; Vol. 12.

${ }^{3}$ C. P. Rader, Vulcanization of Rubber - A. Sulfur and Non-Peroxides. In Basic Elastomer Technology, 1st ed.; K. C. Baranwal, H. L. Stephens, Eds. Rubber Division: Akron, OH, USA, 2001; pp 165-191.

${ }^{4}$ A. Y. Coran, Vulcanization. In The Science and Technology of Rubber, 4th ed.; J. E. Mark, B. Erman, M. Roland, Eds. Academic Press: 2013; pp 337-381.

${ }^{5}$ G. Heideman, R. N. Datta, J. W. M. Noordermeer, B. van Baarle, RuBber CHEM. TECHNOL. 77, 512 (2004).

${ }^{6}$ R. Todeschini, V. Consonni, D. Ballabio, A. Mauri, M. Cassotti, S. Lee, A. West, D. Cartlidge, RubBER CHEM. TECHNOL. 87, 219 (2014).

${ }^{7}$ N. J. Morrison, M. Porter, RubBer Chem. TEChNOL. 57, 63 (1984). 
${ }^{8}$ R. H. Campbell, R. W. Wise, RubBer CHEM. TECHNOL. 37, 635 (1964).

${ }^{9}$ C. G. Moore, B. R. Trego, J. Appl. Polym. Sci. 8, 1957 (1964).

${ }^{10}$ T. D. Skinner, A. A. Watson, RubBer ChEM. TeChNOL. 42, 404 (1969).

${ }^{11}$ D. S. Campbell, J. Appl. Polym. Sci. 14, 1409 (1970).

${ }^{12}$ C. R. Parks, D. K. Parker, D. A. Chapman, W. L. Cox, Rubber ChEM. TeChnOL. 43, 572 (1970).

${ }^{13}$ D. A. Chapman, C. R. Parks, Anal. Chem. 43, 1242 (1971).

${ }^{14}$ C. R. Parks, D. K. Parker, D. A. Chapman, Rubber Chem. TeChnOL. 45, 467, (1972).

${ }^{15}$ B. L. Chan, D. J. Elliott, M. Holley, J. F. Smith, J. Polym. Sci., C Polym. Symp. 48, 61 (1974).

${ }^{16}$ D. L. Hertz, Elastomerics 116, 17 (1984).

${ }^{17}$ P. E. Mallon, W. J. McGill, J. Appl. Polym. Sci. 74, 2143 (1999).

${ }^{18}$ L. González, A. Rodríguez, J. L. Valentín, A. Marcos- Fernández, P. Posadas, Kautsch. Gummi Kunstst. 58, $638(2005)$.

${ }^{19}$ A. M. Zaper, J. L. Koenig, RubBer Chem. TeChnOL. 60, 278 (1987).

${ }^{20}$ J. L. Koenig, RUBBer CHEM. TECHNOL. 73, 385 (2000).

${ }^{21}$ M. Porter, The Chemistry of the Sulfur Vulcanization of Natural Rubber. In The Chemistry of Sulfides, A. V. Tobolsky, Ed. Interscience: New York, NY, USA, 1968; p 165.

${ }^{22}$ J. V. Aleman, A. V. Chadwick, J. He, M. Hess, K. Horie, R. G. Jones, P. Kratochvil, I. Meisel, I. Mita, G. Moad, S. Penczek, R. F. T. Stepto, Pure Appl. Chem. 79, 1801 (2007).

${ }^{23}$ A. V. Chapman, M. Porter, Sulphur Vulcanization Chemistry. In Natural Rubber Science and Technology, A. D. Roberts, Ed. Oxford Science Press: Oxford, UK, 1988; pp 511-620.

${ }^{24}$ D. S. Campbell, A. V. Chapman, J. Nat. Rubb. Res. 5, 246 (1990).

${ }^{25}$ B. Basterra-Beroiz, R. Rommel, F. Kayser, S. Westermann, J. L. Valentín, G. Heinrich, RubBER CHEM. TECHNOL. In-Press. (2016)

${ }^{26}$ K. Boonkerd, C. Deeprasertkul, K. Boonsomwong, RUBBER CHEM. TECHNOL. 89, 450 (2016).

${ }^{27}$ G. M. Bristow, R. F. Tiller, Kautsch. Gummi Kunstst. 23, 55 (1970).

${ }^{28}$ B. Saville, A. A. Watson, RUBber CHEM. TECHNOL. 40, 100 (1967).

${ }^{29}$ M. Porter, Vulcanization of Rubber. In Organic Chemistry of Sulfur, 1st ed.; S. Oae, Ed. Plenum Press: New York, USA, 1977.

${ }^{30}$ A. N. Gent, Trans. Faraday Soc. 50, 521 (1954).

${ }^{31}$ D. W. Huke, C. E. Kendall, Photoelec. Spectrometry Group Bull. 15, 408 (1963). 
${ }^{32}$ P. J. Flory, J. Rehner, J. Chem. Phys. 11, 521 (1943).

${ }^{33}$ W. Obrecht, T. Früh (to Arlanxeo Deutschland GmbH), Patent EP 2311907 A1, Apr. 20, 2001.

${ }^{34}$ S. C. George, K. N. Ninan, S. Thomas, Polym. Polym. Compos. 7, 343 (1999).

${ }^{35}$ S. J. Tao, J. Chem. Phys. 56, 5499 (1972).

${ }^{36}$ M. Eldrup, D. Lightbody, J. N. Sherwood, Chem. Phys. 63, 51 (1981).

${ }^{37}$ W. Brostow, R. Chiu, I. M. Kalogeras, A. Vassilikou-Dova, Materials Letters 62, 3152 (2008).

${ }^{38}$ I. M. Kalogeras, H. E. Hagg Lobland, J. Mater. Educ. 34, 69 (2012).

${ }^{39}$ K. Ueberreiter, G. Kanig, J. Chem. Phys. 18, 399 (1950).

${ }^{40}$ S. Loshaek, J. Polym. Sci. 15, 391 (1955).

${ }^{41}$ P. Mason, Polymer 5, 625 (1964).

${ }^{42}$ C. V. Pious, S. Thomas, Polymeric Materials - Structure, Properties, and Applications. In Printing on Polymers: Fundamentals and Applications, 1st ed.; J. Izdebska, S. Thomas, Eds. William Andrew: 2016; pp $21-40$

${ }^{43}$ J. D. Ferry, R. G. Mancke, E. Maekawa, Y. Oyanagi, R. A. Dickie, J. Phys. Chem. 68, 3414 (1964).

${ }^{44}$ E. Cichomski, W. K. Dierkes, J. W. M. Noordermeer, S. M. Schultz, T. V. Tolpekina, L. A. E. M. Reuvekamp, A. Blume, Paper \#108 presented at the Fall $188^{\text {th }}$ Technical Meeting of Rubber Division, ACS Cleveland, OH, October 13-15, 2015.

${ }^{45}$ K. Bandzierz, L. Reuvekamp, J. Dryzek, W. Dierkes, A. Blume, D. Bielinski, Materials 9, 607 (2016).

${ }^{46}$ R. Srithawatpong, Z. L. Peng, B. G. Olson, A. M. Jamieson, R. Simha, J. D. McGervey, T. R. Maier, A. F. Halasa, H. Ishida, J. Polym. Sci. B 37, 2754 (1999).

${ }^{47}$ P. E. Mallon, C. M. Huang, H. Chen, R. Zhang, Y. C. Jean, M. H. S. Gradwell, Mater. Sci. Forum 363-365, $281(2001)$

${ }^{48}$ A. J. Marzocca, S. Cerveny, W. Salgueiro, A. Somoza, L. Gonzalez, Phys. Rev. E 65, 021801-1 (2002).

${ }^{49}$ W. Salgueiro, A. Marzocca, A. Somoza, G. Consolati, S. Cerveny, F. Quasso, S. Goyanes, Polymer 45, 6037 (2004).

${ }^{50}$ V. O. Jobando, C. A. Quarles, Phys. Stat. Sol. (C) 4, 3759 (2007).

${ }^{51}$ A. L. Rodríguez Garraza, M. A. Mansilla, E. L. Depaoli, C. Macchi, S. Cerveny, A. J. Marzocca, A. Somoza, Polym. Test. 52, 117 (2016).

${ }^{52}$ T. G. Fox, S. Loshaek, J. Polym. Sci. 15, 371 (1955).

${ }^{53}$ G. Gee, J. Polym. Sci. 2, 451 (1947). 
${ }^{54}$ G. R. Taylor, S. R. Darin, J. Polym. Sci. 17, 511 (1955).

${ }^{55}$ M. J. van der Merwe, M. H. S. Gradwell, W. J. McGill, J. Appl. Polym. Sci. 81, 2587 (2001).

${ }^{56}$ C. L. M. Bell, J. I. Cunneen, J. Appl. Polym. Sci. 11, 2201 (1967). 